\title{
Performance and economics of low cost clay cylinder microbial fuel cell for wastewater treatment
}

\author{
Siva Rama Satyam B ${ }^{1}$, Manaswini Behera ${ }^{1}$, Makarand M. Ghangrekar ${ }^{1, *}$ \\ ${ }^{1}$ Department of Civil Engineering, Indian Institute of Technology, Kharagpur - 721302, India \\ *Corresponding Author. Tel.:+91-3222-283440; Fax: +91-3222-282254 \\ E-mail: ghangrekar@civil.iitkgp.ernet.in
}

\begin{abstract}
Current wastewater treatment processes require large amount of power for various treatment units and most of the useful energy available in the wastewater remains unrecovered. With increase in demand for clean treatment technologies, Microbial Fuel Cell (MFC) technology is a viable option for treatment of wastewater, since simultaneous recovery of energy in the form of direct electricity with desired degree of treatment can be achieved in this process. Extensive research on MFCs is going on at laboratory scale but very few pilot scale studies have been reported. An attempt has been made to produce low cost scaled up MFCs fabricated using naturally available cheaper clay material as proton exchange membrane without involving any costly polymer membrane or noble metals for electrode fabrication. The results of the experimental study are promising and encouraging for further scaling up of MFCs.

Economic feasibility of MFCs for treating municipal wastewater having COD of $500 \mathrm{mg} \cdot \mathrm{L}-1$ has been studied. The cost analysis shows that clay material may be suitable option as a membrane in scaling up of MFCs. It needs further study on strength of clay material as membrane to handle higher wastewater flows in larger reactor volume. Although, these clay MFCs were operated for more than six months, the life of this material without deteriorating its functional utility also need attention.
\end{abstract}

Keywords: Earthen cylinder MFC, Proton exchange membrane, Power density

\section{Introduction}

The global energy demand is increasing with exponential growth of population. Unsustainable supply of fossil fuels and the environmental concerns like air pollution and global worming associated with the use of fossil fuels are acting as major impetus for research into alternative renewable energy technologies. The high energy requirement of conventional sewage treatment systems are demanding for the alternative treatment technology which will require less energy for its efficient operation and recover useful energy to make this operation sustainable. In past two decades, high rate anaerobic processes such as up-flow anaerobic sludge blanket (UASB) reactors are finding increasing application for the treatment of domestic as well as industrial wastewaters. Although, energy can be recovered in the form of methane gas during anaerobic treatment of the wastewater, but utilization of methane for electricity generation is not attractive while treating small quantity of low strength wastewater and usually it is flared [1]. Therefore, other alternatives for simultaneous wastewater treatment with clean energy production are much desired.

Microbial fuel cell (MFC) is a promising technology for simultaneous treatment of organic wastewater and bio energy recovery in the form of direct electricity, which has gained much interest in recent years. Conventionally, MFC is made up of an anode chamber and a cathode chamber separated by a proton exchange membrane (PEM). MFCs are devices that use bacteria as the catalysts to oxidize organic matter and generate current. Electrons produced by the bacteria from the substrates i.e., organic matter present in wastewater in this case, are transferred to the anode. The electrons are transported to the cathode through an external circuit and protons are transferred through the membrane internally, where they utilize either oxygen to form water or other chemical oxidants to form reduced product. 
The PEM used in MFC plays a substantial role in the power generation [2]. Despite of the rapid development of separators in recent years, there are limitations such as proton transfer limitation and oxygen leakage, which increase the internal resistance and decrease the MFC performance, and thus limit the practical application of MFCs [3]. Various materials are used by the researchers for separating anode and cathode chambers, including cation exchange membrane, anion exchange membrane, ultrafiltration membranes [4], bipolar membrane [5], microfiltration membrane [6], J-Cloth [7] and salt bridge [8], etc. The advances in separator materials and configurations have opened up new promises to overcome these limitations, but challenges remain for the practical full scale application of MFC for wastewater treatment using this material because of its high production cost and fouling of membrane expected requiring replacement. Recently successful treatment of synthetic and rice mill wastewater has been reported in MFC fabricated using earthen pot acting as membrane and its performance has been compared with MFC fabricated using Nafion membrane $[9,10]$. In terms of organic matter removal and power production it is reported that the earthen pot membrane MFC demonstrated better performance than the Nafion membrane MFC. Better performance of earthen cylinder MFC has been reported without employing commercially available PEM than that of MFC using Nafion as PEM [11]. Utilization of such low cost separator will drastically reduce production cost of MFC and it will help in enhancing its application for small wastewater treatment system.

Extensive research on MFCs is going on at laboratory scale but very few pilot scale studies have been reported. To bring this novel technology from laboratory to pilot scale, an attempt has been made for volumetric comparison of the performance of low cost mediator-less MFCs fabricated using naturally available cheaper clay material as proton exchange membrane instead of costly membrane and without using any catalysts. Economic feasibility of MFCs for treating municipal wastewater having COD of $500 \mathrm{mg} \cdot \mathrm{L}^{-1}$ has been studied.

\section{Methodology}

\subsection{Experimental set-up}

The study was carried out in two laboratory scale up-flow dual chamber MFCs (MFC-1, MFC-2) with outer cathode chamber and inner cylindrical anode chamber without employing commercially available PEM. The anode chamber in both the MFCs was made up of earthen cylinder and the wall (5 mm thick) of the earthen cylinder itself was used as the medium for proton exchange. The working volume of anode chamber of MFC-1 and MFC-2 was $0.6 \mathrm{~L}$ and $3.75 \mathrm{~L}$, respectively. The cathode chamber volume was $4.5 \mathrm{~L}$ and $16 \mathrm{~L}$ in MFC-1 and MFC-2, respectively. Earthen cylinder, made from locally available soil (elements present: Na-1.15\%, Mg- $1.52 \%$, Al-20.50 \%, Si-53.52 \%, K-4.74 \%, Ca-1.15\%, Ti-0.94 \%, Fe$16.48 \%$ ), was used in this study. The MFCs were operated under continuous mode. The wastewater was supplied to the MFCs from the bottom of the anode chamber with the help of peristaltic pump. The effluent leaving the anode chamber at the top was brought to the cathode chamber to work as catholyte, where it was given further aerobic treatment with the help of aerators. Stainless steel mesh having total surface area of $360 \mathrm{~cm}^{2}$ and $2250 \mathrm{~cm}^{2}$ was used as anode electrodes and graphite plates, having total surface area of $250 \mathrm{~cm}^{2}$ and 1562.5 $\mathrm{cm}^{2}$, was used as cathode electrodes in MFC-1 and MFC-2, respectively. The electrodes were connected externally with concealed copper wire through external resistance of $100 \Omega$.

\subsection{MFC Operation}

Synthetic wastewater containing sucrose as a source of carbon having chemical oxygen demand (COD) of about $500 \mathrm{mg} \cdot \mathrm{L}^{-1}$ was used in this study. The sucrose medium was prepared using the composition given by Jadhav and Ghangrekar [12]. During start up, MFCs 
were inoculated with anaerobic sludge collected from septic tank bottom after giving heat pretreatment [13] and required amount of sludge was added to the reactors to maintain the sludge loading rate at $0.1 \mathrm{~kg} \mathrm{COD} \cdot \mathrm{kg} \mathrm{VSS}^{-1} \cdot \mathrm{d}^{-1}$. The influent feed $\mathrm{pH}$ was in the range of 7.2 to 7.8 throughout the experiments. These MFCs were operated at room temperature varying from 26 to $34^{\circ} \mathrm{C}$. Both the MFCs were operated under continuous mode at hydraulic retention time (HRT) of $13 \mathrm{~h}$ and organic loading rate (OLR) of $0.923 \mathrm{~kg}$ COD $\cdot \mathrm{m}^{-3} \cdot \mathrm{d}^{-1}$.

\subsection{Analyses and calculations}

The suspended solids (SS), volatile suspended solids (VSS), and COD were monitored according to APHA standard methods [14]. The elemental composition of the earthen cylinder material was determined by Energy Dispersive X-ray analysis (EDX) scanning electron microscope with oxford EDX detector (JEOL JSM5800, Japan). The voltage and current were measured using a digital multimeter with data acquisition unit (Agilent Technologies, Malaysia) and converted to power according to $P=I^{*} V$; where, $P=$ power, $I=$ current, and $V$ $=$ voltage $(\mathrm{V})$. The Coulombic efficiency $(\mathrm{CE})$ was estimated by integrating the measured current relative to the theoretical current on the basis of consumed COD [15]. Polarization studies were carried out at variable external resistances (10000-10 $\Omega$ ) using $10 \mathrm{~K} \Omega$ variable resistors. Internal resistance of the MFCs was measured from the slope of line from the plot of voltage versus current [16].

\section{Results}

\subsection{Substrate degradation}

The synthetic wastewater having COD of about $500 \mathrm{mg} \cdot \mathrm{L}^{-1}$ was treated anaerobically first in the anode chamber of the MFCs and further aerobic treatment was given to the anode chamber effluent in the cathode chamber. To achieve stable performance in terms COD removal efficiency MFC-1 took about 15 days and MFC-2 took about 13 days. Average COD removal efficiencies in the anode chambers of MFC- 1 and MFC-2 were $77.5 \pm 3.1 \%$ and 86.9 $\pm 2.65 \%$, respectively. After aerobic treatment in the cathode chamber the total COD removal efficiencies of both MFC-1 and MFC-2 were $90.7 \pm 4.2 \%$ and $93.12 \pm 2.6 \%$, respectively. The larger volume MFC (MFC-2) demonstrated higher COD removal efficiency when both the MFCs were operated at similar HRT and OLR. The higher COD removal could be due to better retention of sludge in larger reactor as compared to smaller reactor improving solid retention time, which favors higher substrate degradation rates.

\subsection{Power generation}

Electricity generation in both the MFCs increased gradually with time and got stabilized. Maximum open circuit voltage (OCV) of $0.698 \mathrm{~V}$ and maximum short circuit current (SC) of $6.04 \mathrm{~mA}$ were observed in MFC-1. Maximum OCV of $0.776 \mathrm{~V}$ and maximum SC of $27.6 \mathrm{~mA}$ were obtained in MFC-2. The average electrical output from these MFCs is presented in the Table 1. Sustainable power density (normalized to the anode surface area) of $12.84 \mathrm{~mW} \mathrm{~m}^{-2}$ and volumetric power (normalized to the working volume of anode chamber) of $770 \mathrm{~mW} \cdot \mathrm{m}^{-3}$ $(2.15 \mathrm{~mA}, 0.215 \mathrm{~V})$ were generated at $100 \Omega$ external resistance in MFC-1. MFC-2 generated sustainable power density and volumetric power of $12.11 \mathrm{~m} \mathrm{~W} \cdot \mathrm{m}^{-2}$ and $727 \mathrm{~mW} \cdot \mathrm{m}^{-3}$, respectively. Sustainable volumetric current density with respect to working volume of anode chamber achieved in MFC-1 and MFC-2 were $3.6 \mathrm{~A} \cdot \mathrm{m}^{-3}$ and $1.4 \mathrm{~A} \cdot \mathrm{m}^{-3}$, respectively. Maximum Coulombic efficiency of $5.43 \%$ and $4.49 \%$ was achieved in MFC-1 and MFC-2, respectively. 
Table 1. Power generation in the MFCs at OLR of $0.923 \mathrm{~kg} \mathrm{COD} \cdot \mathrm{m}^{-3} \cdot \mathrm{d}^{-1}$

\begin{tabular}{|c|c|c|c|c|c|c|c|c|}
\hline MFC & $\begin{array}{c}\text { OCV } \\
\text { (V) }\end{array}$ & $\begin{array}{c}\mathrm{SC} \\
(\mathrm{mA})\end{array}$ & $\begin{array}{c}\text { Voltage } \\
\text { across } \\
100 \Omega \\
\text { (V) }\end{array}$ & $\begin{array}{c}\text { Current } \\
\text { density } \\
\text { with } \\
100 \Omega \\
\left(\mathrm{A} \cdot \mathrm{m}^{-3}\right)\end{array}$ & $\begin{array}{c}\text { Power } \\
\text { density } \\
\text { with } 100 \Omega \\
\left(\mathrm{mW} \cdot \mathrm{m}^{-2}\right)\end{array}$ & $\begin{array}{c}\text { Power/vol } \\
\text {.with } \\
100 \Omega \\
\left(\mathrm{mW} \cdot \mathrm{m}^{-3}\right)\end{array}$ & $\begin{array}{l}\text { Max. Power/ } \\
\text { vol. at } \\
\text { optimum } \\
\text { resistance } \\
\left(\mathrm{W} \cdot \mathrm{m}^{-3}\right)\end{array}$ & $\begin{array}{c}\text { Internal } \\
\text { resistance } \\
(\Omega)\end{array}$ \\
\hline MFC-1 & 0.692 & 4.9 & 0.215 & 3.6 & 12.84 & 770.4 & 0.96 & 212.0 \\
\hline MFC-2 & 0.767 & 21.9 & 0.522 & 1.4 & 12.11 & 726.9 & 1.00 & 44.3 \\
\hline
\end{tabular}

Although, the larger volume MFC (MFC-2) demonstrated slightly lower CE (4.49\%) as compared to MFC-1 (CE of $5.43 \%$ ), the volumetric power produced in both these MFCs was similar. This was due to $143 \%$ higher working voltage demonstrated by MFC-2. This higher working voltage observed in MFC-2 could be due to higher working volume and hence having higher surface area of electrodes improving capacitance of the system. Also, the higher cathode surface area might have favored better cathodic reaction by reducing cathodic overpotential and improving voltage produced by this MFC as compared to MFC-1 with lower cathode surface area. Since oxygen is terminal electron acceptor in cathode, reduction of oxygen on cathode surface can occur in two different mechanisms at $25^{\circ} \mathrm{C}$ as:

$\mathrm{O}_{2}+4 \mathrm{H}^{+}+4 \mathrm{e}^{-} \longrightarrow 2 \mathrm{H}_{2} \mathrm{O}\left(\mathrm{E}_{0}=0.816 \mathrm{~V}\right)$

$2 \mathrm{O}_{2}+4 \mathrm{H}^{+}+4 \mathrm{e}^{-} \longrightarrow 2 \mathrm{H}_{2} \mathrm{O}_{2}\left(\mathrm{E}_{0}=0.295 \mathrm{~V}\right)$

Cathode potentials in MFC-1 and MFC-2 were $210 \mathrm{mV}$ and $330 \mathrm{mV}$ without employing any noble catalysts. The typical measured cathode potentials using oxygen as terminal electron acceptor is around $200 \mathrm{mV}$ [15]. The higher cathode potential observed demonstrates the better performance of graphite plate cathode while using earthen material as membrane.

\subsection{Polarization and internal resistance}

Polarization studies were carried out for the MFCs by varying external resistance from 10000 $\Omega$ to $10 \Omega$. Maximum power densities observed during polarization were $15.97 \mathrm{~mW} \cdot \mathrm{m}^{-2}$ at external resistance of $234 \Omega$ in MFC-1 and $16.74 \mathrm{~mW} \cdot \mathrm{m}^{-2}$ at external resistance of $45.5 \Omega$ in MFC-2 (Fig. 1). Internal resistance of the MFCs measured from the slope of line from the voltage versus current plot of MFC-1 and MFC-2 were $212 \Omega$ and $44.3 \Omega$, respectively. In spite of 6.25 times larger surface area of anode provided in MFC-2, it demonstrated slightly higher power density than the MFC-1 provided with lower anode surface area. Also, the larger MFC demonstrated very low internal resistance as compared to smaller MFC, indicating better substrate diffusion and less internal losses in larger MFC. This is particularly encouraging for scaling up of MFC and provides a scope for further increase in anode volume and surface area to obtain similar power density. This experience has demonstrated that, if properly designed, similar energy recovery efficiency can be obtained from the larger MFCs. This will facilitate reducing number of MFCs, to treat same wastewater volume or produce desired power, thus reducing its production cost and also operating complications and cost.

\subsection{Cost Analysis for MFC}

Preliminary cost analysis for MFCs treating municipal wastewater having COD of $500 \mathrm{mg} \cdot \mathrm{L}^{-}$

${ }^{1}$ with anode chamber volume of 201 iters and hydraulic retention time of 10 hour $\mathrm{s}$ was performed. For $1 \mathrm{~m}^{3}$ of wastewater treatment per day number of MFCs required are 21 and each will be treating wastewater flow rate of $48 \mathrm{~L} \cdot \mathrm{d}^{-1}$. With assumed COD removal efficiency of $75 \%$, cell voltage of $0.5 \mathrm{~V}$ and $\mathrm{CE}$ of $30 \%$, the power obtained from each cell is $0.3 \mathrm{~W}$. 
Reversal of voltage in stack of cells is not considered and maintenance cost of the cells and pumping costs are not included in the cost comparison. For treating wastewater flow of 1000 $\mathrm{m}^{3} \cdot \mathrm{d}^{-1}$, total power achieved from MFC plant is $7.9 \mathrm{KW}$. Maximum power available in this wastewater is calculated based on $1 \mathrm{~g} C O D=14.7 \mathrm{~kJ}$ [17]. Fig. 2 presents the power likely to be harvested from the MFCs treating $1000 \mathrm{~m}^{3} \cdot \mathrm{d}^{-1}$ of wastewater flow rate at different Coulombic efficiencies. There is lot of scope for MFC to improve because from the theoretical calculations of power production at different flow rates with assumed voltage of $0.5 \mathrm{~V}$, maximum power achieved from MFCs is $23.6 \mathrm{~kW}$ at CE of $90 \%$ and at flow rate of $1000 \mathrm{~m}^{3} \cdot \mathrm{d}^{-1}$. Maximum power available in wastewater at similar conditions is $63.8 \mathrm{~kW}$.

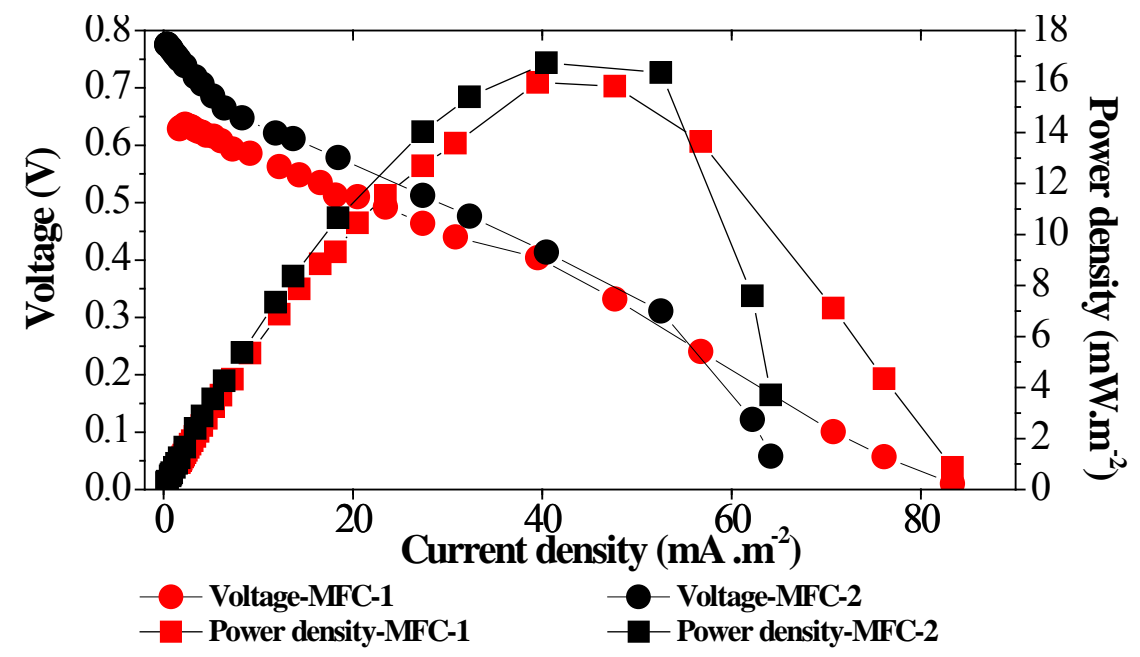

Fig. 1. Polarization curves for MFC-1 and MFC-2

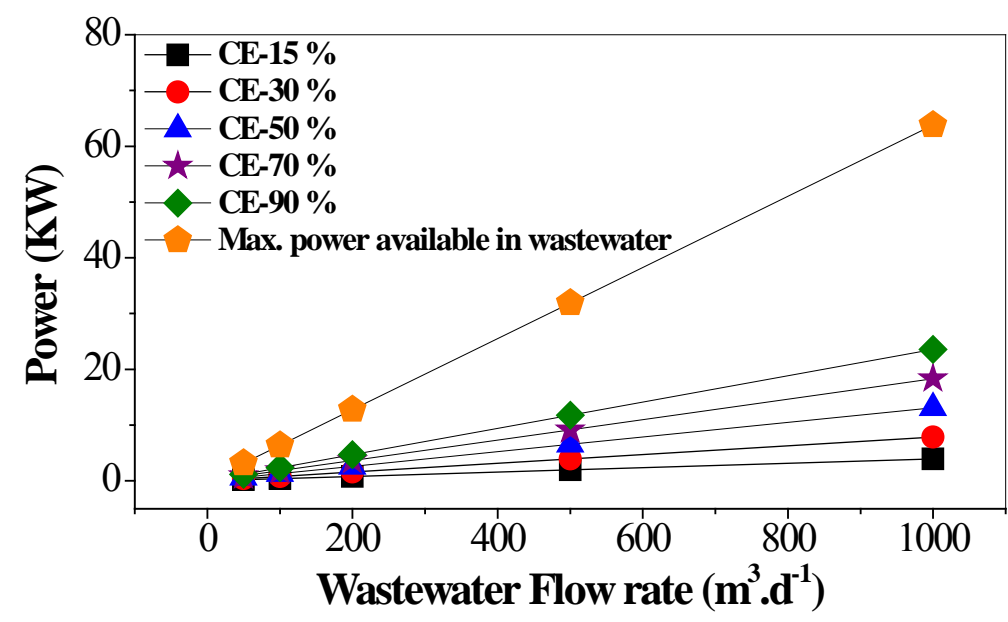

Figure 2 : Power achieved from the MFC treatment plant at different CE and different wastewater flowrates with assumed voltage obtained from each cell of $0.5 \mathrm{~V}$ and COD removal efficiency of $75 \%$.

The materials considered for cell construction are Stainless Steel (SS) mesh as electrode for both anode and cathode, Sintex ${ }^{\mathrm{R}}$ pipe for anode and cathode chamber in case of nafion membrane where 12 slits of $8 \mathrm{~cm} \times 10 \mathrm{~cm}$ were considered on the circumference of anode chember wall for nafion membrane insertion (6 in bottom half and 6 in top half of anode chamber). In the second case, hollow cylindrical earthen pot was considered for fabrication of anode and the pot material acting as a membrane separating anode and cathode and Sintex ${ }^{\mathrm{R}}$ pipe was considered for fabrication of cathode chamber. Cost of each of these materials considered in this study is according to the prevailing Indian market. The approximate costing 
of the MFCs for treatment of different wastewater flows is presented in the Table 2. MFC with earthen material as membrane is a sustainable option for its application in wastewater treatment because of low cost (79\% cost reduction compared to Nafion as membrane) and comparable power generation and treatment efficiency in terms of COD removal than Nafion as membrane. In addition to this no $\mathrm{c}$ hemical mediators are considered in this study to enhance the power production.

Table 2. Total capital cost comparison of MFC plant at different flow rates of wast water

\begin{tabular}{cccc}
\hline $\begin{array}{c}\text { Flow of } \\
\text { wastewater } \\
\left(\mathrm{m} 3 \cdot \mathrm{d}^{-1}\right)\end{array}$ & $\begin{array}{c}\text { Cost of MFC cells } \\
\text { with Nafion membrane } \\
(\text { Rupees })\end{array}$ & $\begin{array}{c}\text { Cost of MFC cells } \\
\text { with earthen pot as } \\
\text { membrane (Rupees) }\end{array}$ & $\begin{array}{c}\% \text { of cost reduction } \\
\text { with earthen material } \\
\text { than Nafion }\end{array}$ \\
\hline 1000 & $159,106,828$ & $32,750,000$ & 79 \\
500 & $79,553,414$ & $16,375,000$ & 79 \\
200 & $31,821,366$ & $6,550,000$ & 79 \\
100 & $15,910,683$ & $3,275,000$ & 79 \\
50 & $7,955,341$ & $1,637,500$ & 79 \\
\hline
\end{tabular}

\section{Discussions}

The overall COD removal efficiency of both the MFCs were more than $90 \%$, which demonstrates the feasibility of this configuration of MFC as an effective wastewater treatment technology and ensures better reliable effluent quality. It was observed that the power generation in the MFC did not change significantly when the volume of the reactor was increased from $0.6 \mathrm{~L}$ to $3.75 \mathrm{~L}$. This result demonstrates that there is further scope in increasing the reactor size.

Jana et al. [11] have reported sustainable power density of $48.30 \mathrm{~m} \mathrm{~W} \cdot \mathrm{m}^{-2}$ in an MFC employing earthen cylinder of $0.6 \mathrm{~L}$ capacity as anode chamber. The power generated in MFC-1 was lower than that obtained by Jana et al. [11]. MFC-1 was in operation over 6 months prior to present study. The reduction in power generation might be due to fouling of earthen cylinder used as separator and decrease in the porosity of the earthen material, which probably has reduced the proton transfer and also due to the reuse of old graphite plate's electrodes. Recently we observed that by polishing the surfaces of graphite plates increased the power generation.

The internal resistance and overpotential losses of MFC-2 are less than MFC-1 which motivates further scaling up of microbial fuel cells with earthen cylinder as PEM. The study was carried out with synthetic wastewater. It needs further study on strength of clay material as membrane for higher wastewater flows and higher reactor volumes. The life of this material without deteriorating its functional utility also needs attention.

Rozendal et al. [18] have compared the anticipated costs of MFCs with the capital costs of the two most widely used conventional wastewater treatment systems, i.e., activated sludge treatment and anaerobic digestion. This comparison shows that, based on the materials currently used in the laboratory, the capital costs of a full scale bioelectrochemical systems would be orders of magnitude higher than those of conventional wastewater treatment systems. The capital cost might be reduced significantly by improving the design and employing innovative materials, but because of the inherently complex design of bioelectrochemical systems, it is expected that the capital cost will always remain several times that of conventional wastewater treatment systems. However, for smaller wastewater flow such as from individual house or from the small group of housing, the cost of MFC may 
become comparable with the other treatment methods and the advantage of direct electricity generation for powering certain onsite appliances can be gained. Also, this process can be best utilized for treatment of wastewater in remote area and generating the power in the form of direct electricity. Thus, the advantage of making electricity available can be utilized along with wastewater treatment in the remote area which is not connected with the electric grid.

The major drawback in MFC as compared to other processes is smaller volume required for anode chamber. Whatsoever the volume of anode, it will deliver maximum voltage of about $0.7 \mathrm{~V}$ and hence, smaller anode volume is desirable for integrating voltage by putting several MFCs in series. Whereas the single large anode of volume equal to that of summation of anode volumes in series will produce only about $0.7 \mathrm{~V}$. Hence, while scaling up a trade-off need to be maintained while finalizing anode volume between the voltage and current recovered. If larger volume MFCs is able to demonstrate similar CE as smaller MFCs, higher current can be recovered from the MFC to maintain similar volumetric power densities. Therefore while scaling the geometrical arrangement and relative positions of the electrodes should be decided in such a way to obtain maximum Coulombic efficiency. Such large size MFCs will then be able to compete with the established alternative wastewater treatment processes in terms of capital investments.

\section{Conclusions}

Clay material was found to be a cheaper alternative to more commonly used expensive Nafion membrane in MFCs. It needs further study on strength of clay material as membrane for higher wastewater flows and higher reactor volumes. A lthough, these clay MFCs were operated for more than six months, the life of this material without deteriorating its functional utility also need attention. It remains to be demonstrated whether the results from this liter scale MFC can be extrapolated to more realistic scales for industrial applications. Full scale implementation of bioelectrochemical system is not straightforward as it includes certain microbiological, technological and economic challenges, which need to be resolved that have not previously been encountered in any other wastewater treatment systems.

\section{Acknowledgement}

The Grant received from the Ministry of Environment and Forest, Government of India (F. No. 19-35/2005-RE) is duly acknowledged.

\section{References}

[1] M.M. Ghangrekar, V.B. Shinde, Wastewater treatment in microbial fuel cell and electricity generation: as ustainable approach. Proceedings of $12^{\text {th }}$ international sustainable development research conference, 2006, Hong Kong, pp. 1-9.

[2] Z. Du, H. Li, T. Gu, A state of the art review on $m$ icrobial fuel cells: A promising technology for wastewater treatment and bioenergy, Biotechnology Advances, 25, 2007, pp. 464-482.

[3] W.W. Li, G.P. Sheng, X.W. Liu, H.Q. Yu, R ecent advances in the separators for microbial fuel cells, Bioresource Technology, 102, 2011, pp. 244-252.

[4] J.R. Kim, S. Cheng, S.E. Oh, B.E. Logan, Power generation using different cation, anion, and ultrafiltration membranes in microbial fuel cells, Environmental Science and Technology, 41, 2007, pp. 1004-1009. 
[5] A. Terheijne, H.V.M. Hamelers, V.D. Wildie, R.A. Rozendal, C.J.N. Buisman, A bipolar membrane combined with ferric iron reduction as an efficient cathode system in microbial fuel cells, Environmental Science and Technology, 40, 2006, pp. 5200-5206.

[6] J. Sun, Y. Hu, Z. Bi, Y. Cao, Simultaneous decolorization of azo dye and bioelectricity generation using a microfiltration membrane air-cathode single-chamber microbial fuel cell, Bioresource Technology, 100, 2009, pp. 3185-3192.

[7] Y. Fan, H. Hu, H. Liu, Enhanced Coulombic efficiency and power density of air-cathode microbial fuel cells with an improved cell configuration, Journal of Power Sources, 171, 2007, pp. 348-354.

[8] B. Min, S. Cheng, B.E. Logan, Electricity generation using membrane and salt bridge microbial fuel cells, Water Research 39, 2005, pp.1675-1686.

[9] M. Behera, P. S. Jana, M.M. Ghangrekar, Performance evaluation of low cost microbial fuel cell fabricated using earthen pot with biotic and abiotic cathode, Bioresource Technology, 101, 2010, pp.1183-1189.

[10]M. Behera, P. S. Jana, T. T., More, M.M. Ghangrekar, Rice mill wastewater treatment in microbial fuel cells fabricated using proton exchange membrane and earthen pot at different pH, Bioelectrochemistry, 79, 2010, pp. 228-233.

[11]P. S. Jana, M. Behera, M.M. Ghangrekar, Performance comparison of up-flow microbial fuel cells fabricated using proton exchange membrane and earthen cylinder, International Journal of Hydrogen Energy, 35, 2010, pp. 5681-5686.

[12] G.S. Jadhav, M.M. Ghangrekar, Improving performance of MFC by design alteration and adding cathodic electrolytes, Applied Biochemistry and Biotechnology, 2008, 151, pp. 319-332.

[13]M.M. Ghangrekar, V.B. Shinde, Performance of membrane-less microbial fuel cell treating wastewater and effect of electrode distance and area on electricity production, Bioresource Technology, 98, 2007, pp. 2879-2885.

[14]APHA, AWWA, WPCF, Standard methods for examination of water and wastewater, Washington, D.C., 20th Ed., 1998.

[15]B.E. Logan, B. Hamelers, R. Rozendal, U. Schroder, J. Keller, S. Freguia, P. Aelterman, W. Verstraete, K. Rabaey, Microbial fuel cells: methodology and technology, Environmental Science and Technology, 40, 2006, pp. 5181-5192.

[16]C. Picioreanu, I.M. Head, K.P. Katuri, M.C.M. van Loosdrecht, K. Scott, A computational model for biofilm-based microbial fuel cells, Water Research 41, 2007, pp. 2921-2940.

[17] I. Shizas, D.M. Bagley, Experimental determination of energy content of unknown organics in municipal wastewater streams, Journal of Energy Engineering, 130, 2004, pp. 45-53.

[18]R.A. Rozendal, H.V.M. Hamelers, K. Rabaey, J. Keller, C.J.N. Buisman, Towards practical implementation of bioelectrochemical wastewater treatment, Trends in Biotechnology, 26, 2008, pp. 450-459. 